\title{
Targeted expression of SV40 T antigen in the hair follicle of transgenic mice
}

\section{produces an aberrant hair phenotype}

\author{
R. Keough, B. Powell* and G. Rogers \\ Department of Biochemistry, University of Adelaide, GPO Box 498, Adelaide, South Australia 5001, Australia \\ ${ }^{*}$ Author for correspondence
}

\section{SUMMARY}

Directed expression of SV40 large T antigen (TAg) in transgenic mice can induce tissue-specific tumorigenesis and useful cell lines exhibiting differentiated characteristics can be established from resultant tumor cells. In an attempt to produce an immortalised mouse hair follicle cortical cell line for the study of hair keratin gene control, SV40 TAg expression was targeted to the hair follicles of transgenic mice using a sheep hair gene promoter. Expression of SV40 TAg in the follicle cortex disrupted normal fiber ultrastructure, producing a marked phenotypic effect. Affected hairs were wavy or severely kinked (depending on the severity of the phenotype) producing an appearance ranging from a ruffled coat to a stubble covering the back of the mouse. The transgenic hairs appeared to be weakened at the base of the fibers, leading to premature hair-loss and a thinner pelage, or regions of temporary nudity. No follicle tumors or neoplasia were apparent and immortalisation of cortical cells could not be established in culture. In situ hybridisation studies in the hair follicle using histone $\mathrm{H3}$ as a cell proliferation marker suggested that cell proliferation had ceased prior to commencement of $\mathrm{K2.10-TAg}$ expression and was not re-established in the differentiating cortical cells. Hence, TAg was unable to induce cell immortalisation at that stage of cortical cell differentiation. However, transgenic mice developed various other abnormalities including vertebral abnormalities and bladder, liver and intestinal tumors, which resulted in reduced life expectancy.

Key words: SV40 T antigen, hair follicle, keratin

\section{INTRODUCTION}

The hair follicle is a complex and dynamic structure which provides an interesting model for the study of development, proliferation and differentiation. The follicle is composed of several different cell types which form the various layers of the outer root sheath and inner root sheath, and the cortical and surrounding cuticle layers of the hair shaft. As the follicle bulb cells divide and rapidly differentiate into cuticle and cortical keratinocytes a complex pattern of gene expression is observed in the follicle cortex, where different keratin genes are activated at different stages of cortical cell differentiation, such that a hierarchy of gene expression is established (Powell et al., 1991, 1992). Keratins are the structural proteins of the hair and form the bulk of the protein synthesised in terminally differentiating keratinocytes. There are 2 major groups of proteins: the keratin intermediate filament (IF) proteins and the keratin-associated proteins (KAP). The keratin IF are composed of two classes, the type I proteins and the type II proteins, which are co-expressed in specific pairs. Four different pairs are found in the hair cortex and these form 8$10 \mathrm{~nm}$ diameter filaments in the cells, embedded in a matrix of KAPs. The KAPs comprise several protein families, each with many highly related members (Gillespie, 1990; Powell and Rogers, 1990b). The first detectable hair-specific keratins are the IF, with the activation of different KAP families occurring at later stages of differentiation (Powell et al., 1991).

The factors controlling the specificity and timing of keratin gene expression in the hair follicle are unknown. Comparison of the promoter regions of sheep hair keratin genes indicates conserved sequence elements that may have functional significance (Powell et al., 1991, 1992). In addition, the sheep hair IF gene promoters also contain sequences identified in epithelial IF genes (Powell et al., 1991), such as AP-2 binding sites, thought to be involved in general keratin expression (Leask et al., 1990, 1991; Snape et al., 1991; Byrne and Fuchs, 1993), AP-1 binding sites and the AARCCAAA binding motif (where $\mathrm{R}$ is a purine nucleotide) (Blessing et al., 1987). Identification of novel consensus sequences in the $5^{\prime}$ flanking regions of these genes is useful as an indicator of the possible involvement of transcription factors and the complexity of transcriptional regulation. However, the functional importance of these proposed regulatory sequences must now be confirmed.

The study of hair keratin gene regulation, and other aspects of hair growth per se, has been hampered by the lack of good in vitro systems; in particular, a follicle keratinocyte cell line. The use of cell lines has been a major tool in studying the molecular and cellular biology of eukaryotic systems but despite the recent successes of primary follicle culture (Philpott et al., 1991; Reynolds and Jahoda, 1991), no permanent cell 
lines exist. Naturally occurring human hair follicle tumors arising in the follicle matrix and displaying limited differentiation toward hair cortical cells and cells of the inner root sheath have been described (for review see Grußendorf-Conen, 1990), but these tumors are extremely rare and have not been used to generate cell lines. However, the targeting of oncogene expression in transgenic mice to produce specific, immortalised cell lines which exhibit differentiated phenotypes has been a considerable breakthrough in many systems, producing useful cell lines where no naturally occurring cell lines previously existed (Paul et al., 1988; Efrat et al., 1988a; Nakamura et al., 1989; Bryce et al., 1993; Lew et al., 1993). In an attempt to produce cell lines from hair cortical cells to facilitate the investigation of hair promoter function and other aspects of hair keratinocyte differentiation, we targeted the expression of SV40 T antigen (TAg) to the cortical cells of transgenic mice using the $5^{\prime}$ promoter region of the sheep KRT2.10 (K2.10) gene (Powell and Rogers, 1990a). The expression of SV40 $\mathrm{TAg}$ in the hair follicles disrupted normal fiber ultrastructure, producing weakened, wavy or kinked hairs, quite unlike those of the hair-loss mice that resulted from over-expression of the complete keratin gene (Powell and Rogers, 1990a). Despite expression of TAg in hair follicle cortical keratinocytes no follicle tumors were observed and no cortical cell immortalisation could be established in vitro. The transgenic mice were also markedly smaller than their non-transgenic littermates, had a reduced life expectancy and developed ectopic tumors.

\section{MATERIALS AND METHODS}

\section{Production of transgenic mice with K2.10-TAg fusion gene}

The $K 2.10$ promoter contains $5^{\prime}$ flanking $/ 5^{\prime}$ untranslated region (UTR) sequence from a HindIII site $(-2800)$ to a $K p n I$ site $(+271)$ in the first exon (Fig. 1). A $2.7 \mathrm{~kb} \mathrm{BamHI/BglI}$ fragment spanning nucleotides 2533-5235 of the SV40 genome was ligated into an engineered SalI site created by site-directed mutagenesis at +53 of a $3 \mathrm{~kb} \mathrm{HindIII/KpnI}$ fragment of the sheep K2.10 gene promoter (Powell and Rogers, 1990a). The resulting $5.7 \mathrm{~kb}$ fusion construct, K2.10-TAg, was microinjected into fertilised mouse oocytes. Microinjection was performed essentially as described by Hogan et al. (1986) and transgenic mice were detected by either dot blot or Southern analysis with a $2.7 \mathrm{~kb} \mathrm{BamHI} / B g l \mathrm{I} T A g$ probe.

\section{Histology and immunocytochemistry}

For histological analysis, mouse dorsal skin was fixed in $4 \%$ paraformaldehyde and embedded in paraffin wax. Sections $(7 \mu \mathrm{m}$ thick) were stained with the tripartite SACPIC stain (Auber, 1950). For immunocytochemistry, unfixed dorsal skin was embedded in OCT compound (Miles Inc., USA.). Cryostat sections (14 $\mu \mathrm{m}$ thick) were air-dried and stained for SV40 TAg using mouse monoclonal antibody Pab 419 (Harlow et al., 1981), ascites fluid kindly supplied by T. Adams (University of Melbourne, Victoria), and used at 5-10 mg/ml, essentially as described by Hanahan (1985). Antigen-antibody complexes were visualised by fluorescein-labelled sheep anti-mouse immunoglobulin (Silenus Laboratories, Australia).

\section{Electron microscopy}

Hairs were prepared for transmission electron microscopy as described by Filshie and Rogers (1961) and ultrathin sections were cut with an LKB ultratome. The sections were post-stained with $2 \%$ uranyl acetate followed by $20 \%$ lead citrate solution. Micrographs were taken using a Philips 300 electron microscope.

\section{Amino acid analysis}

Amino acid analyses of washed mouse hair were conducted by standard procedures. Briefly, the hair was hydrolysed for 22-24 hours in constant boiling $\mathrm{HCl}$ containing $0.1-0.2 \%$ (v/v) phenol. Analysis was performed on a Waters Amino Acid Analyzer by ion-exchange chromatography using ninhydrin detection with a dual wavelength detector at 570 and $440 \mathrm{~nm}$.

\section{cRNA probes}

The K2.10 probe (Powell and Rogers, 1990a) was a 3' non-coding PstI fragment (220 bp) cloned into pGEM-2 (Promega, Madison WI) and linearised with HindIII for the production of RNA antisense probe. The rat histone $H 3$ probe (Chou et al., 1990) was a cDNA fragment $(1.5 \mathrm{~kb})$ cloned into pGEM-3 (Promega) and linearised with SalI for the production of antisense RNA probe. Probes labelled to high specific activity using $\left[\alpha^{35}\right.$ S]UTP $(1000-1500 \mathrm{Ci} / \mathrm{mmol}$; Bresatec, South Australia) were synthesised with either T7 or SP6 RNA polymerase using a Message Maker kit (Bresatec). The length of the $\mathrm{H3}$ probe was reduced by treatment with $40 \mathrm{mM} \mathrm{NaHCO} 3 / 60$ mM Na $2 \mathrm{CO}_{3}, \mathrm{pH} 10.2$, at $60^{\circ} \mathrm{C}$ following the method of Cox et al. (1984).

\section{In situ hybridisation analysis}

Mouse dorsal skin was fixed in $4 \%$ paraformaldehyde and embedded in paraffin wax. Sections $(7 \mu \mathrm{m})$ were cut and transferred to TESPA (Sigma) subbed slides (Rentrop et al., 1986). In situ hybridisations were performed as described by Powell and Rogers (1990a) with the following modification. The final post-hybridisation wash stringency was $0.1 \times \mathrm{SSPE}$ (for $K 2.10$ probe) or $2 \times \mathrm{SSPE}$ (for $H 3$ probe) at $60^{\circ} \mathrm{C}$ for 10 minutes, then at $52^{\circ} \mathrm{C}$ for 30 minutes $(1 \times$ SSPE is $0.18 \mathrm{M} \mathrm{NaCl}$, $0.01 \mathrm{M} \mathrm{Na}_{2} \mathrm{HPO}_{4}, 0.001 \mathrm{M} \mathrm{Na} 2 \mathrm{EDTA}, \mathrm{pH}$ 7.7). The sections were dehydrated, air-dried, dipped in Ilford L4 emulsion (Rogers, 1979) and exposed at $4^{\circ} \mathrm{C}$. Following development (Rogers, 1979), the sections were counterstained with SACPIC stain (Auber, 1950).

\section{RESULTS}

\section{Generation of K2.10-TAg transgenic mice}

A hybrid construct containing the sheep $K 2.105^{\prime}$ promoter sequences fused to the SV40 early region gene, encoding SV40 large $(\mathrm{T})$ and small (t) tumor antigens (Fig. 1), was microinjected into fertilised mouse oocytes. Ten founder (Fo) transgenic animals expressing $\mathrm{K} 2.10-\mathrm{TA} g$ were generated. A line of transgenic mice was established from only one of the ten Fo mice, Fo-40, as the other mice failed to breed. The copy

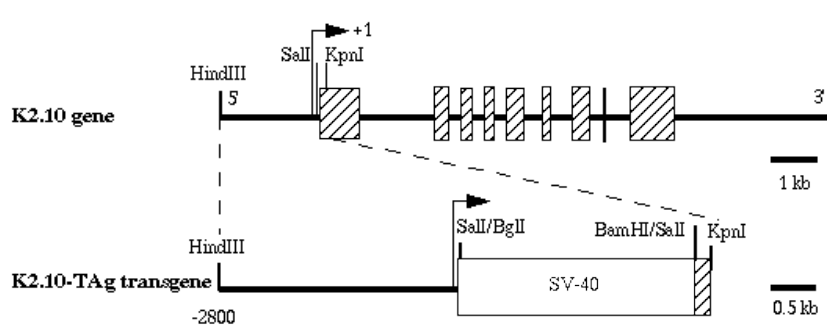

Fig. 1. The K2.10-TAg transgene construct. An SV40 BglI/BamHI restriction fragment encoding both small $(\mathrm{t})$ and large $(\mathrm{T})$ tumor antigens and containing the polyadenylation signals was cloned into the SalI site of a HindIII/KpnI promoter fragment from the $K 2.10$ gene. Sequences $5^{\prime}$ of the SalI/BglI fusion and 3' of the BamHI/SalI fusion are derived from the sheep $K 2.10$ gene as shown. The arrow depicts the transcription start $(+1)$ site; the hatched boxes depict $K 2.10$ exon sequences. 
number of the transgene in these mice was approximately 50 and was stably inherited over at least six generations.

Expression of the transgene was analysed by immunofluorescent staining of mouse pelage follicles using monoclonal antibodies directed against SV40 TAg. Expression was directed to the cortex of the transgenic hair follicles (Fig. 2), following the same pattern observed with the entire K2.10 sheep gene in transgenic mice (Powell and Rogers, 1990a).

\section{Aberrant hair phenotype of K2.10-TAg transgenic mice}

K2.10-TAg transgenic mice exhibited an abnormal hair phenotype which varied in severity amongst the Fo mice. Mice expressing the transgene were initially identifiable by wavy vibrissae, noticeable 2-3 days after birth. Hairs of the pelage were also affected, producing a ruffled coat in the moderate phenotype (Fig. 3A) ranging to stubble covering the back of
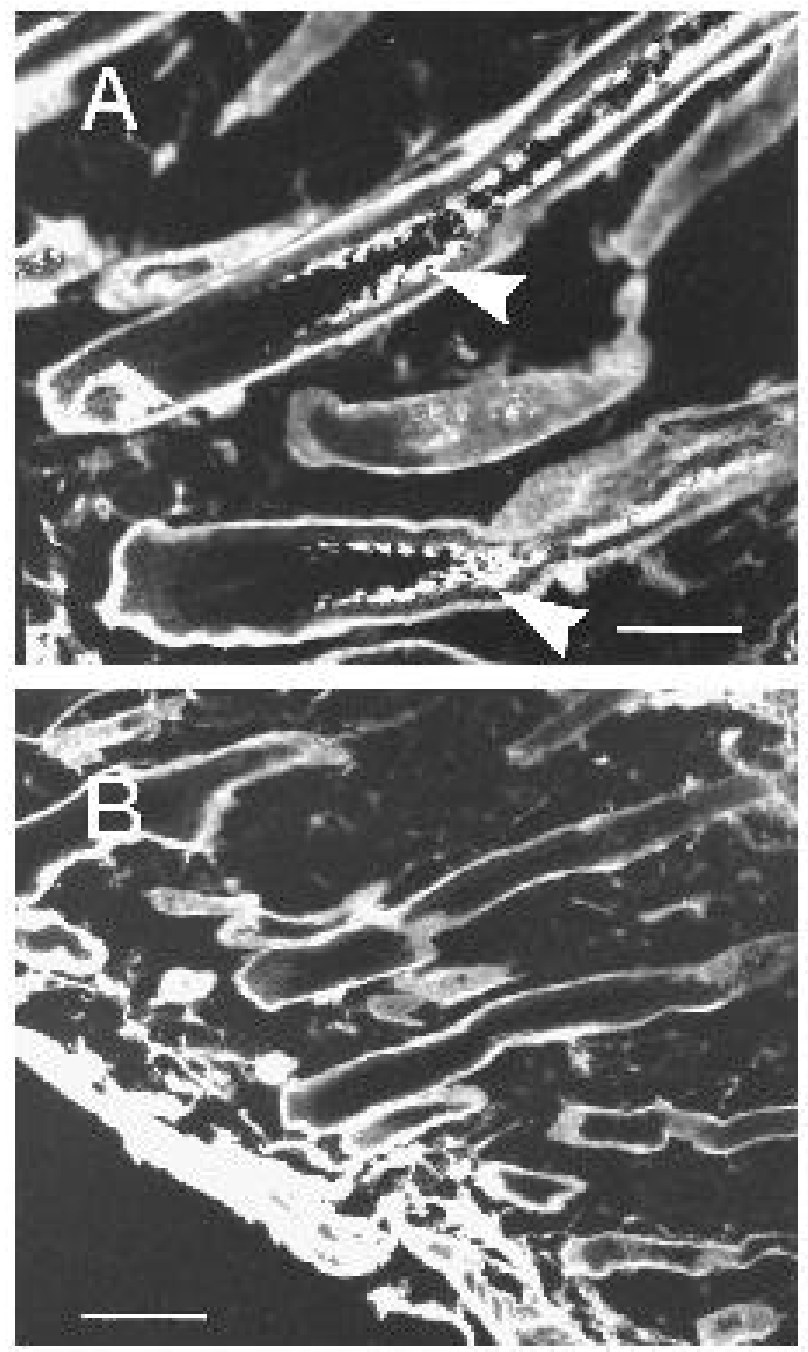

Fig. 2. Expression of the $K 2.10-T A g$ gene in the skin of transgenic mice as determined by immunofluorescent staining. (A) Specific staining with anti-SV40 TAg mAb is localised to the hair follicle cortex (arrowheads); (B) non-specific background staining to outer root sheath and muscle is evident when anti-SV40 TAg mAb is omitted. Note that the skin sections shown are of a moderate phenotype. Bars: (A) $75 \mu \mathrm{m}$; (B) $150 \mu \mathrm{m}$. the mouse in the more severe phenotypes (Fig. 3B,C). Scaling of the epidermis was also evident in severely affected newborn mice (Fo-50, Fo-75 and Fo-94) and the skin of these mice was often wrinkled (Fig. 3C). The transgenic hairs appeared to be weakened at the base, leading to premature hair loss and
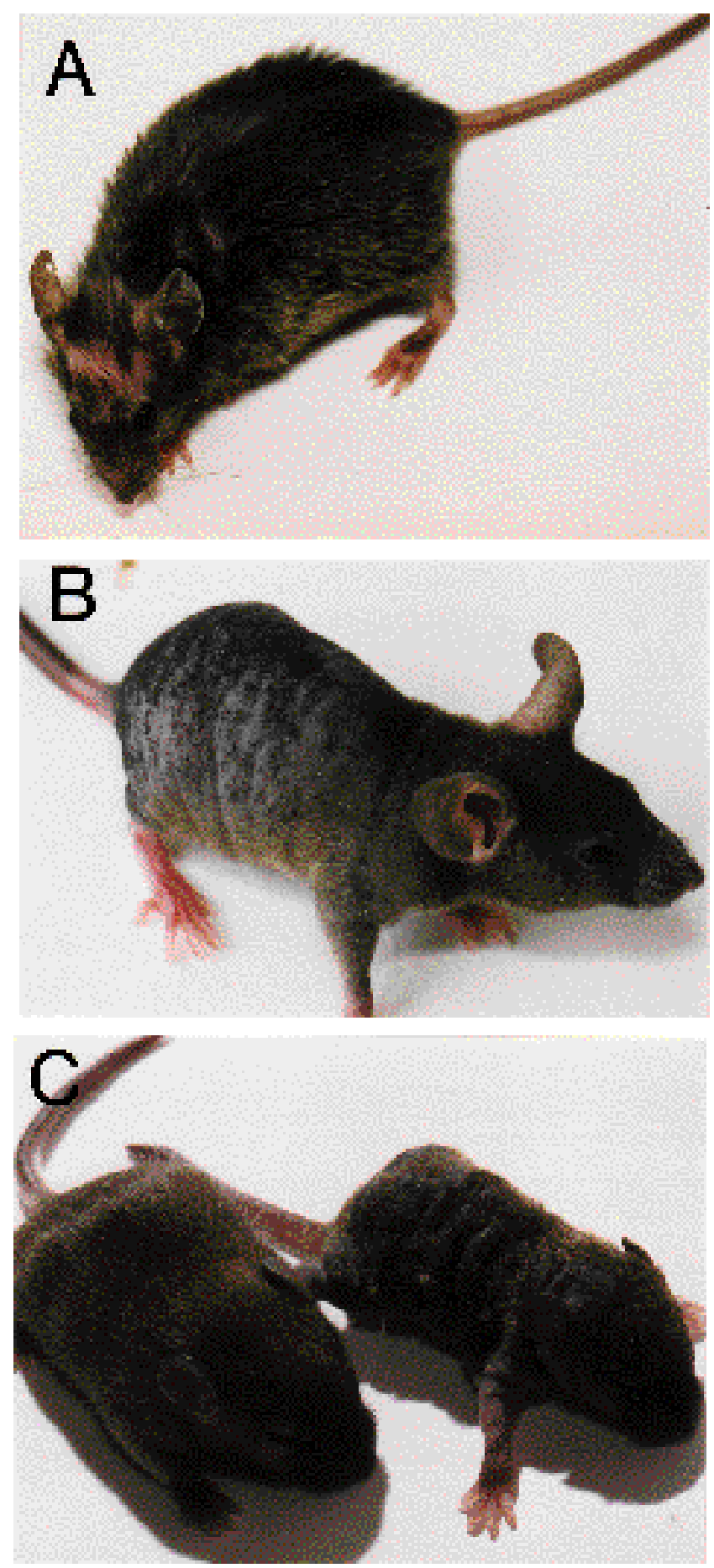

Fig. 3. Aberrant hair phenotype of K2.10-TAg transgenic mice. (A) A 4-month-old transgenic mouse of the no. 40 line showing the moderate transgenic phenotype with a ruffled coat and some hairloss; (B) mouse Fo-119 at 1 month of age showing the stubble typical of a strong transgenic phenotype; (C) mouse Fo-94 (right) along with non-transgenic littermate at 11 days old. 

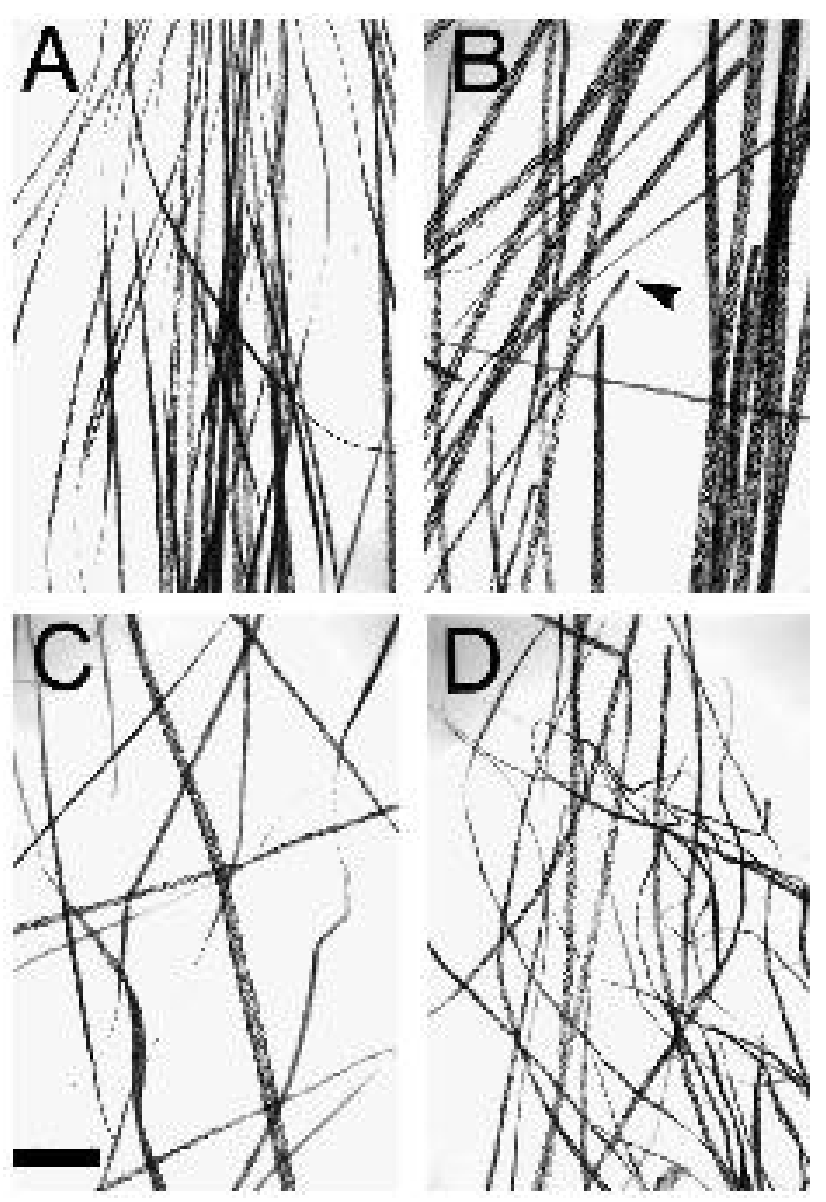

Fig. 4. Hair fiber phenotypes observed by light microscopy. Comparison of hairs from a normal mouse (A) with hairs from the moderate phenotype Fo-40 mouse (B) and the severe phenotype mice Fo-49 (C) and Fo-50 (D). Arrowhead in (B) shows broken fibers typical of plucked hairs from these transgenic mice. The ends of plucked hairs from normal mice are usually encased in a capsule. Bar, $2 \mathrm{~mm}$.

resulting in a thinner pelage or regions of temporary nudity, depending on the severity of the phenotype. When viewed by light microscopy, plucked hairs from K2.10-TAg mice show deformities which are absent in normal mice (Fig. 4A). This varies from a slight crookedness along the fiber shaft in some hairs of the moderate phenotype (no. 40 line, Fig. 4B) to a noticeable kinkiness and fiber deformation in the more severe phenotypes such as Fo-49 and Fo-50 (Fig. 4C,D).

Skin sections from transgenic mice showed that many follicles from mice with a moderate phenotype appeared virtually normal (Fig. 5A,B), with few malformed hair shafts. Skin sections from Fo-49 and Fo-50 mice (Fig. 5C,D), which exhibited severe phenotypes, show extensive follicle abnormalities and deformed, folded hairs, many of which appear encysted and unable to pierce the epidermis. An inflammatory response was also evident in dermis of these severely affected mice.

Electron micrographs of the transgenic hairs show that the fibers are composed of a mixed population of normal cortical cells and abnormal cells in which the cellular ultrastructure appears grossly altered (Fig. 6A,B). Normal cortical cells

Table 1. Amino acid compositions of hair from K2.10-TAg transgenic mice and normal mice

\begin{tabular}{|c|c|c|c|c|c|}
\hline & Normal* & $K 2.10^{\dagger}$ & $\mathrm{F}_{3}-40.3 \ddagger$ & $\mathrm{F}_{3}-40.36 \S$ & $\mathrm{F}_{0}-127$ \\
\hline Asp & 5.2 & 7.3 & 6.2 & 6.7 & 6.1 \\
\hline Thr & 4.7 & 4.5 & 4.6 & 4.5 & 4.6 \\
\hline Ser & 9.6 & 8.1 & 8.7 & 8.0 & 8.6 \\
\hline Glu & 13.0 & 16.1 & 15.0 & 16.2 & 14.5 \\
\hline Pro & 6.8 & 4.6 & 6.0 & 5.9 & 6.0 \\
\hline Gly & 10.4 & 8.7 & 9.0 & 8.3 & 9.3 \\
\hline Ala & 4.2 & 6.3 & 5.0 & 5.2 & 4.8 \\
\hline Cys & 13.6 & 7.9 & 10.2 & 9.2 & 10.9 \\
\hline Val & 4.2 & 5.2 & 4.6 & 4.7 & 4.4 \\
\hline Met & 0.8 & 1.1 & 1.0 & 1.1 & 1.0 \\
\hline Ile & 2.3 & 3.2 & 2.7 & 2.9 & 2.7 \\
\hline Leu & 6.2 & 8.2 & 7.1 & 7.7 & 7.0 \\
\hline Tyr & 5.0 & 3.2 & 4.1 & 3.8 & 4.5 \\
\hline Phe & 2.7 & 2.9 & 2.9 & 3.0 & 2.9 \\
\hline His & 1.1 & 1.1 & 1.3 & 1.4 & 1.2 \\
\hline Lys & 3.0 & 4.9 & 3.8 & 4.3 & 3.7 \\
\hline Arg & 7.0 & 6.5 & 7.7 & 6.9 & 7.7 \\
\hline \multicolumn{6}{|c|}{$\begin{array}{l}\text { *Normal littermate of } \mathrm{F}_{3}-40.36 \text {. } \\
\dagger K 2.10 \text { hair-loss transgenic mouse from Powell and Rogers (1990a). } \\
\left.\ddagger \mathrm{F}_{3} \text { mouse from no. } 40 \text { line (heterozygous for } K 2.10-T A g\right) \text {. } \\
\left.\mathrm{F}_{3} \text { mouse from no. } 40 \text { line (homozygous for } K 2.10-T A g\right) \text {. } \\
{ }_{[} \mathrm{F}_{0}-127 \text {, severe phenotype. }\end{array}$} \\
\hline
\end{tabular}

exhibit a 'fingerprint pattern' characteristic of the closely packed ordered arrays of IFs and densely staining KAPs. This pattern is less obvious or completely absent in the abnormal cells, appearing instead as a densely stained structureless mass. Clearly, keratin assembly and packing is disrupted in these abnormal cortical cells.

To further investigate the abnormal ultrastructure of the cortical cells of the transgenic hairs amino acid analyses were carried out on transgenic hair samples. Table 1 shows the amino acid composition of hair from 2 mice of the no. 40 line, a severe phenotype Fo mouse (Fo-127) and a K2.10 hair-loss transgenic mouse (Powell and Rogers, 1990a), and a normal mouse sample. There are significant differences in the composition of many amino acids between the K2.10-TAg transgenic and normal mouse hair sample, the most dramatic differences being in hairs from $\mathrm{F}_{3}-40.36$ which is homozygous for $\mathrm{K} 2.10$ $T A g$. Large, notable changes are an increase in glutamic acid/glutamine and a decrease in glycine and cysteine levels.

\section{Other aspects of the K2.10-TAg phenotype}

The K2.10-TAg transgenic phenotype was not restricted to the hairs. Transgenic mice were generally smaller than non-transgenic littermates and some showed severely retarded growth rates (Fig. 3C). The vertebrae were also affected. Four Fo mice, including Fo-40, had kinks in the tail, as did many but not all of the transgenic progeny of line no. 40. X-ray analysis of mouse Fo-40 showed malformed vertebral discs in the tail and curvature of the spine (data not shown). Mice with spinal abnormalities often developed partial paralysis of the hind legs. All transgenic mice had a reduced life expectancy ranging from a few days to 9 months (Table 2), which generally correlated with the severity of the hair phenotype. Many of the mice developed tumorous growths in the bladder or intestine (data not shown). Despite the occurrence of these abnormalities, none of the transgenic mice developed tumors in the skin or 
Table 2. Mortality of K2.10-TAg mice

\begin{tabular}{lcll}
\hline Mouse & Copy number* & Lifespan $\dagger$ & \multicolumn{1}{c}{ Phenotype } \\
\hline $\mathrm{F}_{0}-49$ & $25-50$ & 3 months & Severe; paralysis of hind legs \\
$\mathrm{F}_{0}-50$ & $10-25$ & 24 days & Very severe \\
$\mathrm{F}_{0}-75$ & $5-10$ & 17 days & Very severe \\
$\mathrm{F}_{0}-94$ & $25-50$ & 11 days & Very severe \\
$\mathrm{F}_{0}-119$ & $10-25$ & 5 months & Severe \\
$\mathrm{F}_{0}-127$ & 50 & 2.5 months & Severe \\
$\mathrm{F}_{0}-131$ & $10-25$ & 4 months & Moderate \\
$\mathrm{F}_{0}-138$ & $1-5$ & 6 months & Moderate \\
$\mathrm{F}_{0}-144$ & $10-25$ & 3 months & Severe \\
$\mathrm{F}_{0}-40$ & $25-50$ & 5.5 months & Moderate; paralysis of hind legs \\
$\mathrm{F}_{1}-40.2$ & $25-50$ & 5 months & Moderate \\
$\mathrm{F}_{1}-40.3$ & $25-50$ & 6 months & Moderate \\
$\mathrm{F}_{1}-40.9$ & $25-50$ & 9 months & Moderate; intestinal tumor; liver \\
& & & secondaries \\
$\mathrm{F}_{2}-40.5$ & $25-50$ & 5 months & Moderate; bladder tumor \\
$\mathrm{F}_{3}-40.6$ & $25-50$ & 3.5 months & Moderate; bladder tumor \\
& &
\end{tabular}

hair follicles and microscopic inspection of hair follicle sections failed to show neoplastic lesions in any of the mice.

\section{Comparison of the zones of cell proliferation and differentiation in the hair follicle bulb}

To determine whether the absence of neoplasia in the follicle was due to targeting TAg expression too late in the differentiation pathway of the cells the expression patterns of histone $H 3$ and $K 2.10$ were examined using in situ hybridisation to mRNA. Histone $\mathrm{H} 3 \mathrm{mRNA}$ is synthesised during $\mathrm{S}$ phase of the cell cycle but is present in $\mathrm{G}_{1}$ and $\mathrm{G}_{2}$ and can therefore be used to detect cycling cells (Chou et al., 1990). A comparison of histone $\mathrm{H3}$ with $\mathrm{K2} .10$ expression was performed on consecutive whisker follicle sections taken from mice transgenic for the sheep K2.10 gene (Powell and Rogers, 1990a). K2.10 transgenic mice were used because the high level of transgene expression allowed easy detection as we were unable to detect TAg mRNA by this technique in K2.10-TAg transgenic follicles (although immunostaining did show the presence of TAg; see Fig. 2).

Expression of histone $H 3$ was seen in the bulb region of the follicle up to the top of the dermal papilla (Fig. 7A,C). K2.10 mRNA was detected in the cortex of the follicle, appearing above the tip of the dermal papilla, 2-3 cells above the level of histone $H 3$ expression (Fig. 7B,D,E). Histone $H 3$ expression in 2.10-TAg transgenic follicles was identical to that observed in $K 2.10$ transgenic follicles, i.e. expression did not appear above the dermal papilla (Fig. 7C,F). Despite the expression of TAg protein in cells higher up in the follicle no histone $H 3$ expression and, by inference, no cellular proliferation was seen in those cells.

\section{DISCUSSION}

\section{Expression of SV40 TAg}

The expression of the sheep $K 2.10$ gene, used to target SV40 $\mathrm{TAg}$ expression to the follicle cortex in the present study, has previously been analysed in transgenic mice (Powell and Rogers, 1990a). The gene encodes an IF type II keratin protein and high level expression in mice produces a hair-loss phenotype. The $3 \mathrm{~kb}$ K2.10 gene promoter fragment encompassing the immediate $5^{\prime}$ flanking $/ 5^{\prime}$ UTR sequence is sufficient to direct the expression of SV40 TAg to the hair follicle cortex (see Fig. 2), maintaining the localisation and timing of expression of the endogenous $K 2.10$ gene in the sheep follicle and the expression of the larger transgene seen in the $K 2.10$ hair-loss transgenic mice.

Growth retardation, tumor formation in the bladder and intestine, and vertebral abnormalities in K2.10-TAg mice appear to be a consequence of TAg expression as different Fo mice show the same phenotype, and TAg mRNA has been detected in an intestinal tumor from one of these mice (data not shown). In the K2.10-TAg mice it is not known whether TAg expression in the tumors is promiscuous or whether low level expression of hair keratins normally occurs in these tissues or subsets of cells within them. Non-follicular transgene expression may be due to the lack of tight controlling sequences, gene silencers for example, which lie outside of the $3 \mathrm{~kb} K 2.10$ gene promoter fragment used to drive $\mathrm{TAg}$ expression. Interestingly, there are reports of novel expression patterns of several chimeric genes in transgenic mice where expression occurs in tissues in which the targeting promoter is normally inactive (Behringer et al., 1988; Lew et al., 1993). In growth hormone factor-1/TAg mice (Lew et al., 1993), expression of TAg occurs in resultant intestinal tumors but not in the adjacent nontumorous intestinal tissue, suggesting that only a subset population of cells was affected. In mouse protamine-1 ( $\mathrm{mPl}$ )/SV40 mice (Behringer et al., 1988) ectopic expression was thought to be due to novel regulatory elements generated by the juxtaposition of the $\mathrm{mPl}$ promoter and $T A g$ sequences.

Hair-like keratins have been found in hoof, claw and nail in several species (Marshall and Gillespie, 1977; Lynch et al., 1986; Heid et al., 1988), and in tongue and thymus (Heid et al., 1988), although no abnormalities in those tissues were seen in $\mathrm{K2.10-TAg}$ mice (data not shown).

\section{Effects of SV40 TAg on hair and follicle morphology}

Expression of SV40 TAg in the cortical cells of the hair follicle has obvious effects on the morphology of the hairs and whiskers of mice (Figs 3, 4). In transgenic mice with a moderate phenotype the pelage fibers were crooked and the whiskers were distinctly curly, but follicle morphology appeared virtually normal. In the more severe phenotypes (Fo49 and Fo-50) the follicles, fibers and skin were grossly affected. Many hairs appeared so weakened and malformed that they could not penetrate the epidermis, producing ingrown hairs. The follicles themselves were grossly altered in their morphology and an inflammatory response in the skin was evident.

The expression of several transgenes in mouse follicles has been shown to affect hair and follicle morphology (Powell and Rogers, 1990a; Blessing et al., 1993; Missero et al., 1993), producing wavy fibers and hair-loss. Unlike the overexpression of sheep $K 2.10$ in the mouse follicle, cyclic hair-loss is not seen in the $\mathrm{K2}$.10-TAg mice. In the less severe phenotypes it appears that the limited hair-loss is due to abrasion, as hair-loss occurs predominantly on the underside of the mice (especially on suckling mothers) and around the snout and head where scratching is more frequent. This suggests an increased brit- 

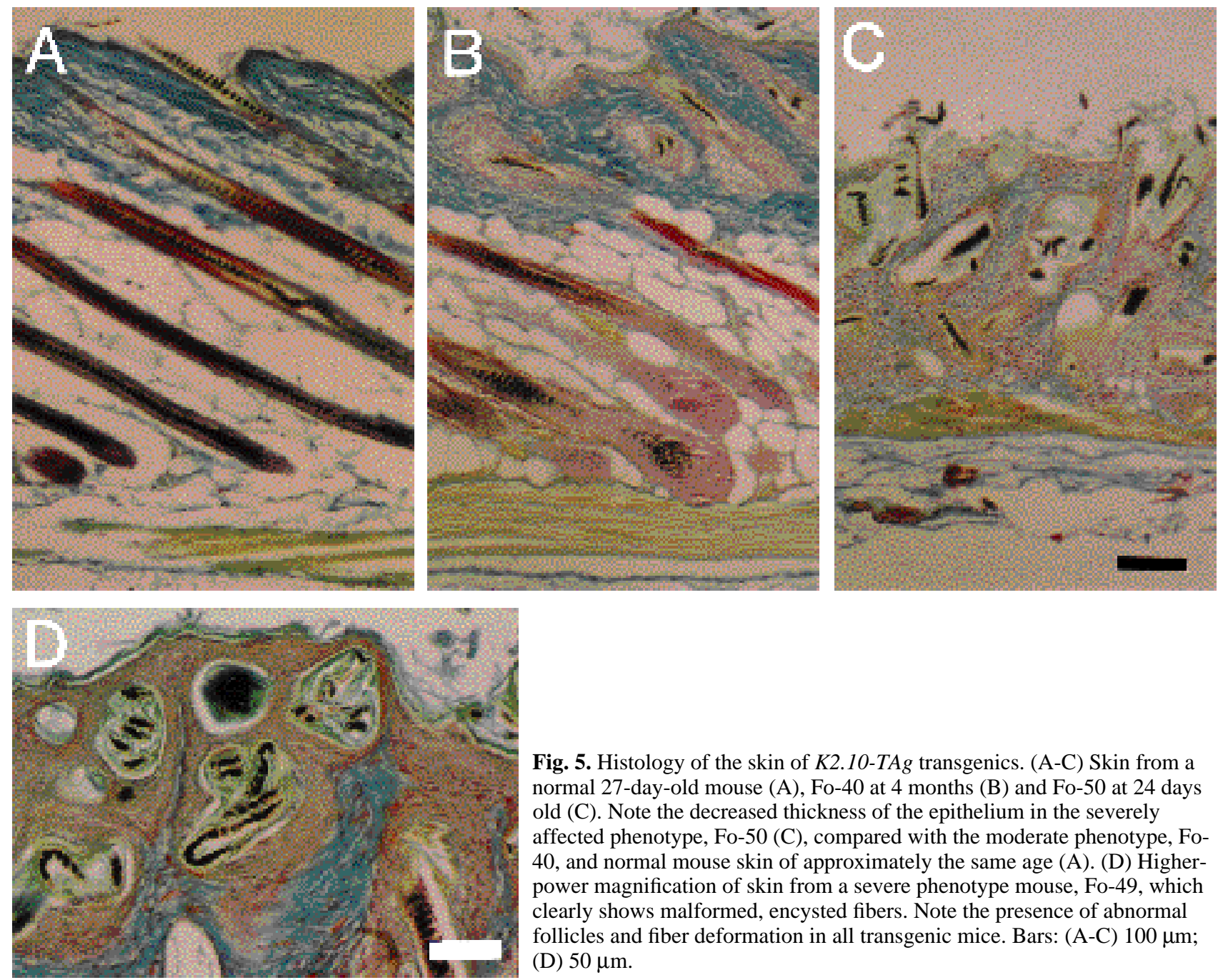

Fig. 5. Histology of the skin of $K 2.10-T A g$ transgenics. (A-C) Skin from a normal 27-day-old mouse (A), Fo-40 at 4 months (B) and Fo-50 at 24 days old $(\mathrm{C})$. Note the decreased thickness of the epithelium in the severely affected phenotype, Fo-50 (C), compared with the moderate phenotype, Fo40 , and normal mouse skin of approximately the same age (A). (D) Higherpower magnification of skin from a severe phenotype mouse, Fo-49, which clearly shows malformed, encysted fibers. Note the presence of abnormal follicles and fiber deformation in all transgenic mice. Bars: (A-C) $100 \mu \mathrm{m}$; (D) $50 \mu \mathrm{m}$.

tleness or susceptibility to breakage but not as severe as in the $K 2.10$ hair-loss mice. Similar phenomena occur in follicles of mice carrying the naked $(N)$ gene (Raphael et al., 1982) and in

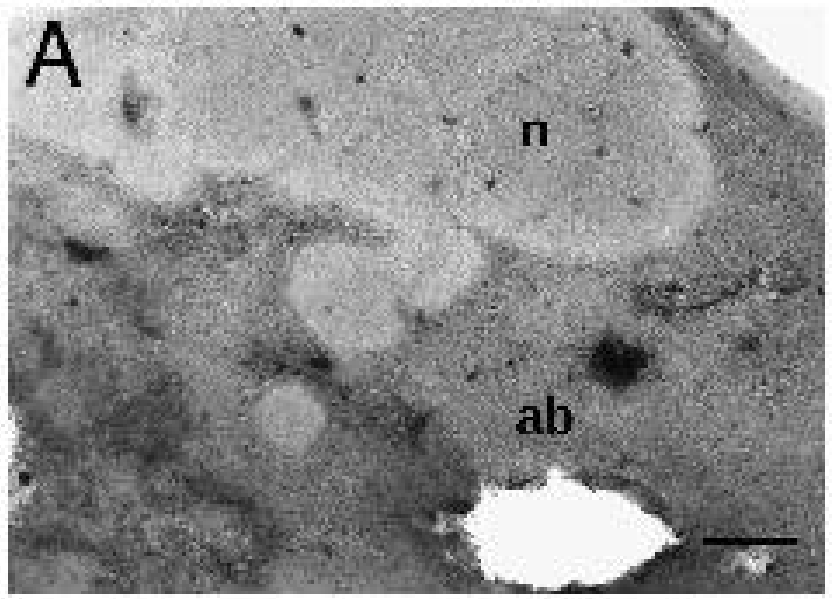

wool follicles of wheat-fed sheep given methionine supplements (Chapman and Reis, 1978), where poor keratinisation of the cortical cells produces weakened fibers and limited hair-

Fig. 6. Electron micrograph of follicle cortical cells from Fo-49 transgenic mouse. (A) Transgenic fibers contain a mixture of both normal (n) and abnormal (ab) cells. (B) Higher magnification of cortical cells showing the distinct ultrastructure of normal cortical cells (n) and the abnormal cells (ab), which appear devoid of structure. Bars: (A) $300 \mathrm{~nm}$; (B) $100 \mathrm{~nm}$. 

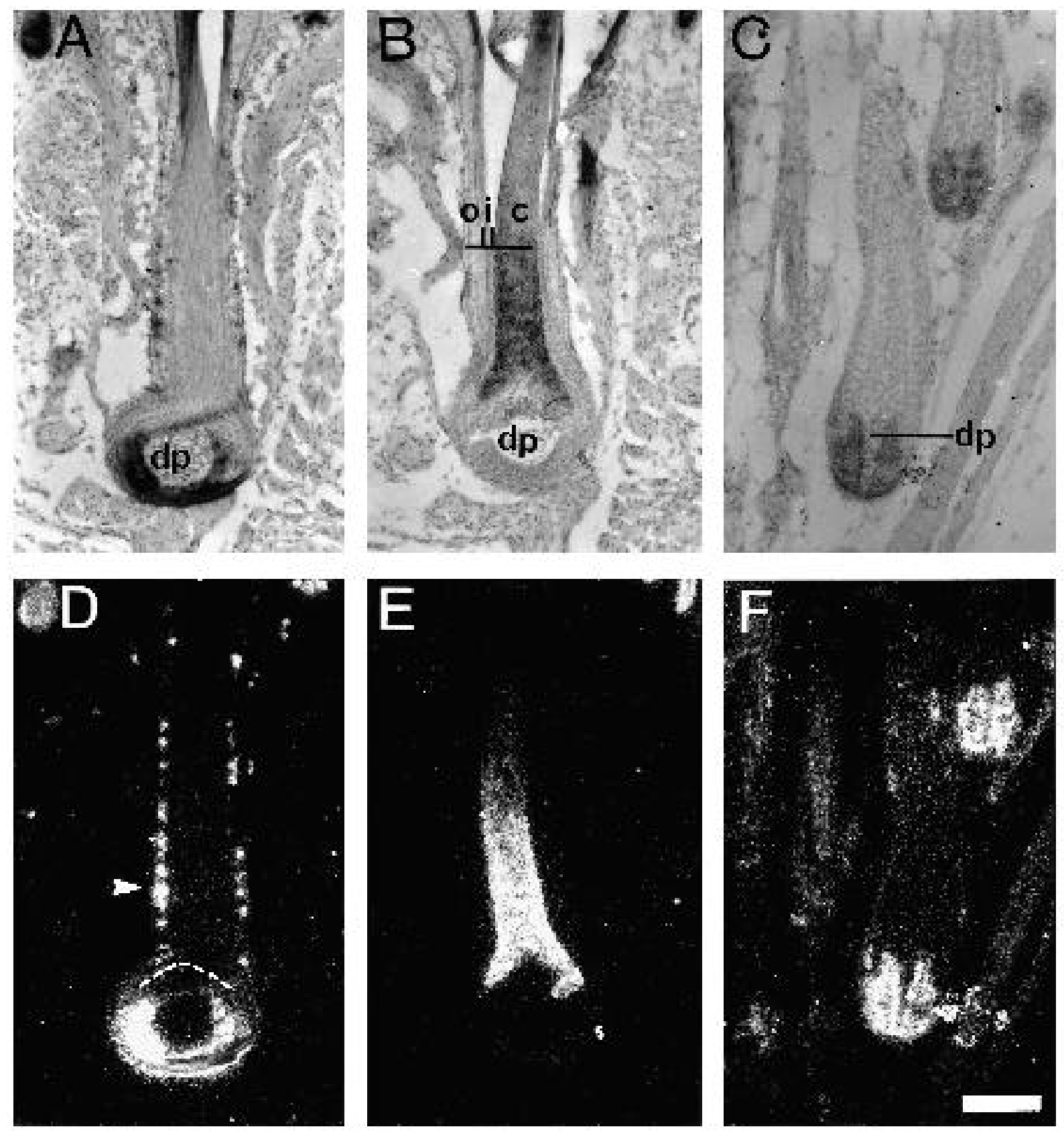

Fig. 7. Comparison of histone $H 3$ expression with expression from the $K 2.10$ promoter in the hair follicle by in situ hybridisation. Consecutive whisker follicle sections from $K 2.10$ transgenic mice were probed for $H 3$ expression (A, D) and $K 2.10$ expression (B, E). Note that expression of $K 2.10$ is first detectable in cells 2-3 cell layers above the top of the dermal papilla and above follicle bulb cells showing $H 3$ expression (D; broken line). (C, F) $H 3$ expression in $K 2.10-T A g$ transgenic pelage follicles. Note that $H 3$ expression does not continue past the top of the dermal papilla. Expression is shown as dark grains under brightfield microscopy (A-C) and as white grains under darkfield (D-F). Also note regions of $H 3$ expression in the ORS (o) of the follicle (arrowhead). dp, dermal papilla; o, outer root sheath; i, inner root sheath; c, cortex and cuticle. Bar, $100 \mu \mathrm{m}$.

loss in moderate phenotypes, whilst severe phenotypes show gross follicle deformation similar to that seen in the skin of Fo49 and Fo-50 mice (Fig. 5).

SV40 TAg expression altered the ultrastructure of the cortical cells, and affected cells lack the ordered arrays of IF, appearing as a structureless mass in electron micrographs (Fig. 6), suggesting that macrofibril formation is incorrectly organised or retarded. The amino acid analysis data show changes in the levels of many amino acids, most notably cysteine, glycine and glutamine/glutamic acid. These changes are not consistent with the composition of TAg and therefore it is unlikely that the disruption of cellular ultrastructure is due to high-level overexpression of TAg. This was borne out by the inability to detect TAg by Western blotting of crude transgenic follicle extracts or TAg mRNA by in situ hybridisation (data not shown). These data suggest that the expression of the transgene alters the 
normal protein composition of the cortical cells. The decrease in the content of cysteine, glycine and tyrosine in the transgenic hairs is consistent with a decrease in the cysteine-rich KAP families and the glycine/tyrosine-rich KAP families. It should also be noted that a decrease in cysteine-rich proteins was also seen in transgenic mice in which K2.10 was overexpressed (see Table 1). This was attributed to competition for common transcription factors and/or steric hindrance of the increased amounts of IF protein, preventing translation of later KAP mRNAs (Powell and Rogers, 1990a).

The expression of a foreign protein per se in the follicle (for example, $\beta$-galactosidase) will not necessarily produce morphological changes in the follicle or fiber (unpublished results). It is not known how TAg is effecting the change in hair protein composition and it is possible that the hair phenotype of these transgenic mice is an indirect consequence of the systemic effect of TAg in various internal organs. The protein itself is present in the abnormal cortical cells and therefore the nuclearlocalised TAg could be acting at the level of gene transcription, as it is known to bind transcription factors such as AP-2 (Mitchell et al., 1987), which may be involved in the expression of hair keratin genes (Powell et al., 1991).

The presence of fibers composed of normal and abnormal cortical cells in the $\mathrm{K2.10-TAg}$ mice is an interesting phenomenon. It is possible that several Fo mice may have been chimeras (no offspring could be obtained to determine this) and, given the polyclonal nature of hair follicle origin (Schmidt et al., 1987), it would then be possible to obtain fibers composed of mixed cortical cell populations. However, this does not explain the stable, heritable mosaic pattern of abnormal and normal cortical cells in the no. 40 line. A similar heritable mosaic pattern of reporter gene expression was seen in the intestinal villi of a pedigree of L-fatty acid binding protein-human growth hormone $(L-F A B P-h G H)$ transgenic mice (Roth et al., 1991). In these mice, polyclonal villi comprised both hGH-positive and hGH-negative enterocyte populations. It was postulated that this expression pattern arose from 'position-effect variegation' (Karpen and Spradling, 1991) associated with the mosaic expression of transgenes inserted adjacent to a junction between euchromatin and heterochromatin. We have observed hair follicle mosaicism in at least 2 Fo K2.10-TAg mice (e.g. Fo-40 and Fo-50), and in several other transgenic mice using a shorter $K 2.10$ promoter fragment or a hair follicle KAP gene promoter (unpublished results). These genes may be predisposed to insertion at euchromatin/heterochromatin junctions or this phenomenon may be more frequent than is reported.

\section{Lack of follicle cell immortalisation}

Immortalisation of many different cell types has been achieved through the targeted expression of SV40 TAg in transgenic mice (for example, Behringer et al., 1988; Paul et al., 1988; Yamada et al., 1990; Bryce et al., 1993; Cartier et al., 1993), with many of the resultant cell lines maintaining differentiated characteristics. We reasoned that, in using the sheep $K 2.10$ promoter to drive TAg expression in the cortical cells of the follicle, the differentiation-dependent expression of $\mathrm{TAg}$ would enable us to obtain useful cell lines with cortical cell characteristics. However, despite the occurrence of tumors in various tissues of the transgenic mice, no hyperplasia or neoplasia was detected in the hair follicles.
Although rare, tumors containing differentiated hair cells do occur (for review, see Grußendorf-Conen, 1990). Benign pilomatricomas, arising from cells of the follicle matrix and exhibiting some limited differentiation toward cortical and inner root sheath cells, do not become vasculated and undergo spontaneous involution. It has been suggested that the duration of growth of the matrix cells in the tumor mimics the normal anagen time of the follicle from which it was derived (Headington, 1976). In the case of the K2.10-TAg mice it was possible that the rapid cellular differentiation, keratinisation and migration of cortical cells up the follicle would not allow sufficient time for immortalisation to occur before the cells were extruded with the mature hair without access to nutrients. It is known that cell immortalisation is a multistep process and may require several months to occur, whilst the growing phase of a mouse hair follicle is 14 days (Hardy, 1949). To allow time for cell immortalisation to occur, intact hair follicles were isolated from 2-4-day-old transgenic mice (according to Rogers et al., 1987) and maintained in culture. Other than fibroblasts, no cell proliferation was evident after prolonged culturing (2-3 months) and TAg protein was no longer detectable in follicles after 5-6 days in culture (data not shown).

TAg protein expression in responsive cells generally results in an increased proliferative capacity and extension of lifespan, even in pre-immortal cells (for review see Hanahan, 1988), as it appears that TAg can overcome proliferation controls which operate in the $\mathrm{G}_{1}$ phase of the cell cycle and can stimulate DNA synthesis in quiescent and senescent cells (Dobbelstein et al., 1992; Rubelj and Pereira-Smith, 1994). Given the potent effect of TAg on cellular proliferation, the lack of hyperplasia in the follicle suggested that the cortical cells in which TAg was expressed were no longer capable of undergoing cell division and had permanently exited from the cell cycle. The in situ hybridisation study of sheep $K 2.10$ expression patterns in transgenic mouse follicles compared with the cell proliferation marker, histone $H 3$, showed that cell proliferation had ceased before $K 2.10$ expression was detectable and was not re-established in hair cortical cells expressing the K2.10-TAg transgene. Therefore, it seems likely that TAg is unable to induce re-entry into the cell cycle at this point in the hair keratinocyte differentiation pathway.

Targeting of TAg expression in transgenic mice using a promoter which is active only in post-mitotic cells has produced immortalised cell lines (Suri et al., 1993). However, despite normally being post-mitotic, cells at this stage of development must still be 'competent' to undergo cell division such that TAg can stimulate re-establishment of proliferation. The same cell population has not been able to be immortalised when TAg expression is targeted to a later stage in the development of these cells (Efrat et al., 1988b). In order to produce a follicle-specific cell line through targeted transgenesis, TAg expression must be targeted earlier in follicle differentiation where cell division is still possible.

We thank Dr R. Seamark of the Department of Obstetrics and Gynaecology (University of Adelaide) for the use of microinjection facilities; Leonie Hicks for performing the microinjections and Vicki Tragenza for skin biopsies; Gail Hermanis of the Department of Anatomy (University of Adelaide) for embedding tissue sections; and Munif Allanson and Zan Min Song for the tissue sectioning; Dr 
Lyndsay M. Dowling of the Commonwealth Scientific and Industrial Research Organization, Division of Wool Technology (Parkville, Victoria, Australia) for the amino acid analyses; and Michael Calder for hair section preparation for electron microscopy. This work was supported by a postgraduate scholarship from the Australian Wool Corporation and by grants from the Australian Wool Corporation to G. E. Rogers.

\section{REFERENCES}

Auber, L. (1950). The anatomy of follicles producing wool fibres with special reference to keratinization. Trans. R. Soc. Edinb.52, 191-254.

Behringer, R. R., Peschon, J. J., Messing, A., Gartside, C. L., Hauschka, S. D., Palmiter, R. D. and Brinster, R. L. (1988). Heart and bone tumors in transgenic mice. Proc. Nat. Acad. Sci. USA 85, 2648-2652.

Blessing, M., Zentgraf, H. and Jorcano, J. L. (1987). Differentially expressed bovine cytokeratin genes. Analysis of gene linkage and evolutionary conservation of 5'-upstream sequences. EMBO J. 6, 567-575.

Blessing, M., Nanney, L. B., King, L. E., Jones, C. M. and Hogan, B. L. M. (1993). Transgenic mice as a model to study the role of TGF- $\beta$-related molecules in hair follicles. Genes Dev. 7, 204-215.

Bryce, D. M., Liu, Q., Khoo, W., Tsuii, L.-C. and Breitman, M. L. (1993). Progressive and regressive fate of lens tumors correlates with subtle differences in transgene expression in $\gamma \mathrm{F}$-crystallin-SV40 $\mathrm{T}$ antigen transgenic mice. Oncogene 8, 1611-1620.

Byrne, C. and Fuchs, E. (1993). Probing keratinocyte and differentiation specificity of the human K5 promoter in vitro and in transgenic mice. Mol. Cell. Biol. 13, 3176-3190.

Cartier, N., Lacave, R., Vallet, V., Hagege, J., Hellio, R., Robine, S., Pringault, E., Cluzeaud, F., Briand, P., Kahn, A. and Vandewalle, A. (1993). Establishment of renal proximal tubule cell lines by targeted oncogenesis in transgenic mice using the L-pyruvate kinase-SV40 (T) antigen hybrid gene. J. Cell Sci. 104, 695-704.

Chapman, R. E. and Reis, P. J. (1978). Effects of abomasal supplements of methionine on the wool follicles and skin of wheat-fed sheep. Aust. J. Biol. Sci. 31, 161-172.

Chou, M. Y., Chang, A., McBride, J., Donoff, B., Gallagher, G. and Wong, D. (1990). A rapid method to determine proliferation patterns of normal and malignant tissues by $\mathrm{H} 3$ mRNA in situ hybridization. Am. J. Pathol. 136, 4.

Cox, K. H., DeLeon, D. V., Angerer, L. M. and Angerer, R. C. (1984). Detection of mRNAs in sea urchin embryos by in situ hybridisation using asymmetric RNA probes. Dev. Biol. 101, 485-502.

Dobbelstein, M., Arthur, A. K., Dehde, S., van Zee, K., Dickmanns, A. and Fanning, E. (1992). Intracistronic complementation reveals a new function of SV40 T antigen that cooperates with $\mathrm{Rb}$ and $\mathrm{p} 53$ binding to stimulate DNA synthesis in quiescent cells. Oncogene 7, 837-847.

Efrat, S., Linde, S., Kofod, H., Spector, D., Delannoy, M., Grant, S., Hanahan, D. and Baekkeskov, S. (1988a). Beta-cell lines derived from transgenic mice expressing a hybrid insulin gene-oncogene. Proc. Nat. Acad. Sci. USA 85, 9037-9041.

Efrat, S., Teitelman, G., Anwar, M., Ruggerio, D. and Hanahan, D. (1988b). Glucagon gene regulatory region directs oncoprotein expression to neurons and pancreatic $\alpha$ cells. Neuron 1, 605-613.

Filshie, B. K. and Rogers, G. E. (1961). The fine structure of $\alpha$-keratin. J. Mol. Biol. 3, 784-786.

Gillespie, J. M. (1990). The proteins of hair and other hard $\alpha$-keratins. In Cellular and Molecular Biology of Intermediate Filaments (ed. R. D. Goldman and P. M. Steinert), pp. 95-128. New York: Plenum Press.

Grußendorf-Conen, E.-I. (1990). Adnexal cysts and tumors of the scalp. In Hair and Hair Diseases (ed. C. E. Orfanos and R. Happle), pp. 699-716. Berlin: Springer.

Hanahan, D. (1985). Heritable formation of pancreatic $\beta$-cell tumours in transgenic mice expressing recombinant insulin/simian virus 40 oncogenes. Nature 315, 115-122.

Hanahan, D. (1988). Dissecting multistep tumorigenesis in transgenic mice. Annu. Rev. Genet. 22, 479-519.

Hardy, M. H. (1949). The development of mouse hair in vitro with some observations on pigmentation. J. Anat. 83, 364-384.

Harlow, E., Crawford, L. V., Pim, D. C. and Williamson, N. M. (1981). Monoclonal antibodies specific for simian virus 40 tumor antigens. J. Virol. 39, 861-869.
Headington, J. T. (1976). Tumors of the hair follicle. Am. J. Path. 85, 480-505.

Heid, H. W., Moll, I. and Franke, W. W. (1988). Patterns of expression of trichocytic and epithelial cytokeratins in mammalian tissues. II. Concomitant and mutually exclusive synthesis of trichocytic and epithelial cytokeratins in diverse human and bovine tissues (hair follicle, nail bed and matrix, lingual papilla, thymic reticulum). Differentiation 37, 215-230.

Hogan, B., Costantini, F. and Lacy, E. (1986). Manipulating the Mouse Embryo. Cold Spring Harbour Laboratory Press, Cold Spring Harbour, NY.

Karpen, G. H. and Spradling, A. C. (1991). Reduced DNA polytenization of a minichromosome region undergoing position-effect variegation in Drosophila. Cell 63, 97-107.

Leask, A., Rosenberg, M., Vassar, R. and Fuchs, E. (1990). Regulation of a human epidermal keratin gene: sequences and nuclear factors involved in keratinocyte-specific transcription. Genes Dev. 4, 1985-1998.

Leask, A., Byrne, C. and Fuchs, E. (1991). Transcription factor AP2 and and its role in epidermal-specific gene expression. Proc. Nat. Acad. Sci. USA 88, 7948-7952.

Lew, D., Brady, H., Klausing, K., Yaginuma, K., Theill, L. E., Stauber, C., Karin, M. and Mellon, P. L. (1993). GHF-1-promoter-targeted immortalization of a somatotropic progenitor cell results in dwarfism in transgenic mice. Genes Dev. 7, 683-693.

Lynch, M. H., O'Guin, W. M., Hardy, C., Mak, L. and Sun, T.-T. (1986). Acidic and basic nail/hair ('hard') keratins: their colocalization in upper cortical and cuticle cells of the human hair follicle and their relationship to 'soft' keratins. J. Cell Biol. 103, 2593-2606.

Marshall, R. C. and Gillespie, J. M. (1977). The keratin proteins of wool, horn and hoof from sheep. Aust. J. Biol. Sci.30, 389-400.

Missero, C., Serra, C., Stenn, K. and Dotto, P. G. (1993). Skin-specific expression of a truncated E1a oncoprotein binding to p105-Rb leads to abnormal hair follicle maturation without increased epidermal proliferation. J. Cell Biol. 121, 1109-1120.

Mitchell, P. J., Wang, C. and Tjian, R. (1987). Positive and negative regulation of transcription in vitro: enhancer-binding protein AP-2 is inhibited by SV40 T antigen. Cell 50, 847-861.

Nakamura, T., Mahon, K., Miskin, R., Dey, A., Kuwabara, T. and Westphal, H. (1989). Differentiation and oncogenesis: phenotypically distinct lens tumors in transgenic mice. New Biol. 1, 193-204.

Paul, D., Hohne, M., Pinkert, C., Piasecki, A., Ummelmann, E. and Brinster, R. L. (1988). Immortalized differentiated hepatocyte lines derived from transgenic mice harboring SV40 T-antigen genes. Exp. Cell Res. 175, 354-362.

Philpott, M. P., Westgate, G. E. and Kealey, T. (1991). An in vitro model for the study of human hair growth. Ann. NY Acad. Sci. 642, 148-164.

Powell, B. and Rogers, G. (1990a). Cyclic hair-loss and regrowth in transgenic mice overexpressing an intermediate filament gene. EMBO J. 9, 1485-1493.

Powell, B. C. and Rogers, G. E. (1990b). Hard keratin IF and associated proteins. In Cellular and Molecular Biology of Intermediate Filaments (ed. R. D. Goldman and P. M. Steinert), pp. 267-300. New York: Plenum Press.

Powell, B., Nesci, A. and Rogers, G. (1991). Regulation of keratin gene expression in the hair follicle. Ann. NY Acad. Sci. 642, 1-20.

Powell, B., Crocker, L. and Rogers, G. (1992). Hair follicle differentiation: expression, structure and evolutionary conservation of the hair type II keratin intermediate filament gene family. Development 114, 417-433.

Raphael, K. A., Chapman, R. E., Frith, P. A. and Pennycuik, P. R. (1982). The structure of hair and follicles of mice carrying the naked (N) gene. Genet. Res. 39, 139-148.

Rentrop, M., Knapp, B., Winter, H. and Schweizer, J. (1986). Aminoalkylsilane-treated glass slides as support for in situ hybridization of keratin cDNAs to frozen tissue sections under varying fixation and pretreatment conditions. Histochem. J. 18, 271-276.

Reynolds, A. J. and Jahoda, C. A. B. (1991). Hair follicle stem cells? A distinct germinative epidermal cell population is activated in vitro by the presence of hair dermal papilla cells. J. Cell Sci. 99, 373-385.

Rogers, A. W. (1979). Techniques in Autoradiography. Elsevier/North Holland Biomedical Press, Amsterdam.

Rogers, G. E., Martinet, N., Steinert, P., Wynn, P., Roop, D., Kilkenny, A., Morgan, D. and Yuspa, S. (1987). Cultivation of murine hair follicles as organoids in a collagen matrix. J. Invest. Dermatol. 89, 369-379.

Roth, K. A., Hermiston, M. L. and Gordon, J. I. (1991). Use of transgenic mice to infer the biological properties of small intestinal stem cells and to examine the lineage relationships of their descendants. Proc. Nat. Acad. Sci. USA 88, 9407-9411.

Rubelj, I. and Pereira-Smith, O. M. (1994). SV40-transformed human cells 
in crisis exhibit changes that occur in normal cellular senescence. Exp. Cell Res. 211, 82-89.

Schmidt, G. H., Blount, M. A. and Ponder, B. A. J. (1987). Immunochemical demonstration of the clonal organization of chimeric mouse epidermis. Development 100, 535-541.

Snape, A. M., Winning, R. S. and Sargent, T. D. (1991). Transcription factor AP-2 is tissue-specific in Xenopus and is closely related or identical to keratin transcription factor 1 (KTF-1). Development 113, 283-293.

Suri, C., Fung, B. P., Tischler, A. S. and Chiaraishi, D. M. (1993).
Catecholaminergic cell lines from the brain and adrenal glands of tyrosine hydroxylase-SV40 T antigen transgenic mice. J. Neurosci. 13, 1280-1291.

Yamada, T., Nakamura, T., Westphal, H. and Russell, P. (1990). Synthesis of $\alpha$-crystallin by a cell line derived from the lens of a transgenic animal. Curr. Eye Res. 9, 31-37.

(Received 3 June 1994 - Accepted 3 November 1994) 